\title{
Will Live Organ Donations No Longer Be Justified?
}

\author{
by THOMAS E. STARZL
}

THOMAS E. STARZL, M.D. is professor of surgery at the University of Pinsburgh School of Medicine.

\footnotetext{
$\mathrm{F}$

or years physicians and ethicists have agued over the relative risks and benefits of soliciting bidney donations from living relatives. Studies have cited the advantages of such altruistic behavior to donors and to society, as well as the emotional and physical toll to family members who were asked to donate organs. Now, bowever, the debate over ethical issues shous signs of withering away. Nor that these issues have been resolved. Far from it. But improvements in the tochnology of organ transplantationparticularly the use of the antirejection drug cyclosporin-have altered the clinical picture radically. Soon, if current trends continue, it may be hard to justify using living donors.
} 
Before 1979, discussions dominated the literature comparing the poor results obthined using unrelaved cadarer bidneys with success rates fo intertamily orensplants, which were estimsted wo bo dbout 30 percent higher. In that year, cyclosporinsteroid therapy was introduced into clinical medicine, bringing with it a striking improvement in the outlook for patients who had undergone cadaver transplants. Modical centers that regularly use cyclosporine therapy' now repon one-year cadaveric graft survival of betier than 75 percent. In some series one-year grafi survival has run as high as 90 percent, using randomly matched organs and unrelated donors. Thus, one year after surgery, the results for cadaver transplants have become competitive with those for intrafamily transplants, thereby greatly reducing the survival advantage for the latter group of patients.

In light of these developments, many thoughtful physicians, as well as prospective rocipients and potential family donors, are reconsidering the advisability of living related donations. Such a reassessment is welcome considering the ethical questions raised by the history of transplants using living donors.

The legal basis for a living donor Dephrectomy was established in Massachusetts in 1954 in a docision involving identical twins. The judge ruled that the overall loss to a recipient of his identical twin brother-including its poychiatric repercussions-would be more harmful than the mere loss of a kidney. The same reasoning has since been applied in other family combinations, even in cases where there is no blood relationship (as between husband and wife, for example). The Massachusetts decision resulted in the first successful bidney transplant with identical twin donor-rocipients at the Peter Bent Brigham Hospital in Boston.

Because the body rejects tissue from all but identical twins, other types of organ donations involving living relatives had to swait the development of immunosuppressive drugs, such as imuran and prednisose. In 1959 the first successful transplant took place between nonidentical twins.

The ethical questions raised by the use of live donors involve both physical and emotional factors. The removal of a bidney from a healthy, well motived donor has been said to be safe, and this is true statistically speaking. Yet an estimated twenty donors have died after the removal of one bidney and most of these tragic deaths have occurred at very good institutions. Furthermore, the morbidity reported by all centers that do a significant number of transplants has been surprisingly and distressingly high. 
As the University of Minnesota Transplant Center a 1974 study reported a 28.2 percent complication rate for live donors. Most complications were minor, but four major complications were recorded. In three cases donors later developed the same disease as the recipient, which may or may not have been related to the donation; one needed dialysis for two months. A pulmonary embolus and a case of deep thrombophlebitus, both related to the operation and both treated successfully, were also recorded (Giff of Life: The Social and Psychological Impact of Organ Transplantation, by Roberta G. Simmons, Susan D. Klein and Richard L. Simmons New York, John Wiley \& Sons, Inc., 1977). In view of such clinical information, is it ever ethical to encourage relatives to donate organs?

Emotional pressures imvolve the possible uses of coercion and persuasion to obtain a donation, and the implications for potential donors, who may foel that they do not have absolute froodom of choice. Critics have asked whether it is ethical to encourage donations, considering the ambivalance of donors, their fears of surgery, their concerns abour the furture, and the resentment they may feel for the person who needs the organ. A major ethical issue concerns the extent of family pressure placed on a donor. both as it exists or is perceived in the mind of the donor. In years past, there were many instances of donors who felt coerced by other family members, but who were unable to resist such pressures, even when members of the transplantation team, ware of their reluctance, provided them with good medical excuses. In our JudeoChristian society, in which self-sacrifice is a working ethic, more courage may be required to resist organ donation than to accept it. 
On the positive side of the ethical equation have been arguments abour the benefits to the donor of being allowed to help others, especially a close family member. Studies have shown that donors foel happier and better about themselves after successful transplant surgery, and that these foelings may increase during the first year. Benefits myy also accrue to a society that allows Itruistic acts. It has also been argued that a person has an obligation to help another human being to live, provided that the risks of doing so are minimal.

But support for living donors has rested on clinical evidence showing that these transplants were more successful. Now that may no longer be the case.

Does that mean that healthcare professionals should stop asking living relatives to donate organs? That would be premature for several reasons. First, we need to determine that the improvements of cadaver transplant surgery are lasting, by looking at long-lerm data on survival and quality of life. Second, there are still not nearly enough cadaver organs to go round.

But knowing what we now know, should we $g \circ$ on encouraging living relatives to provide organs-taking whatever risks that entails-when families of brain dead people may never be asked whether they wish to donate their dead relatives organs?

Is it ethical to harm the living before harvesting the dead? Such questions need to be debated in the light of changing clinical information. 